\title{
Specific Plasma Oxylipins Increase the Odds of Cardiovascular and Cerebrovascular Events in Patients with Peripheral Artery Disease
}

\begin{tabular}{|c|c|}
\hline Journal: & Canadian Journal of Physiology and Pharmacology \\
\hline Manuscript ID & cjpp-2016-0615.R1 \\
\hline Manuscript Type: & Article \\
\hline Date Submitted by the Author: & 04-Jan-2017 \\
\hline Complete List of Authors: & $\begin{array}{l}\text { Caligiuri, Stephanie; St. Boniface Hospital, ICS } \\
\text { Aukema, Harold M.; St. Boniface Hospital, Canadian Centre for Agri-food } \\
\text { Research in Health and Medicine; University of Manitoba, Human } \\
\text { Nutirtional Sciences } \\
\text { Ravandi, Amir; St. Boniface General Hospital, Interventional Cardiology } \\
\text { Lavallee, Renee; St. Boniface Hospital, ICS } \\
\text { Guzman, Randolph; St Boniface Hospital, } \\
\text { Pierce, Grant; Division of Stroke and Vascular Disease, }\end{array}$ \\
\hline $\begin{array}{r}\text { Is the invited manuscript for } \\
\text { consideration in a Special } \\
\text { Issue?: }\end{array}$ & IACS Sherbrooke 2016 special issue Part 1 \\
\hline Keyword: & $\begin{array}{l}\text { Lipidomics, Myocardial Infarction, Cerebrovascular Accident, Oxylipin, Fatty } \\
\text { acid }\end{array}$ \\
\hline
\end{tabular}



Specific Plasma Oxylipins Increase the Odds of Cardiovascular and Cerebrovascular Events in Patients with Peripheral Artery Disease

3 Stephanie P.B. Caligiuri M.Sc ${ }^{1-3}$, Harold M. Aukema Ph.D ${ }^{1,4}$, Amir Ravandi M.D. Ph. $D^{2,3,5}$,

4 Renée Lavallée B.Sc ${ }^{1,2}$, Randy Guzman M.D ${ }^{6}$, Grant N. Pierce Ph.D ${ }^{1-3}$

$5 \quad{ }^{1}$ Canadian Centre for Agri-food Research in Health and Medicine (CCARM) and ${ }^{2}$ the Institute of

6 Cardiovascular Sciences, St. Boniface Hospital Research Centre Winnipeg, Canada, and ${ }^{3}$ the

7 Departments of Physiology, ${ }^{4}$ Human Nutritional Sciences, ${ }^{5}$ Internal Medicine, and ${ }^{6}$ Surgery,

8 University of Manitoba, Winnipeg, Canada

9 Running Title: Oxylipins and CV Events

10 Address for correspondence:

11 Drs Grant Pierce, Harold Aukema and Amir Ravandi, St Boniface Hospital Research Centre, 351

12 Taché Avenue, Winnipeg, MB, Canada R2H 2A6; Tel: 204-235-3206; Fax: 204-235-0793; E-

13 mail: gpierce@sbrc.ca

14 Word Count: 4,500 


\section{Abstract}

16 Oxylipins and fatty acids may be novel therapeutic targets for cardiovascular disease. The

17 objective was to determine if plasma oxylipins or fatty acids can influence the odds of

18 cardiovascular/cerebrovascular events. In 98 patients (25 female, 73 male) with peripheral artery

19 disease, the prevalence of transient ischemic attacks, cerebrovascular accidents, stable angina

20 and acute coronary syndrome was $n=16,10,16$, and 24 , respectively. Risk factors such as being

21 male, diagnosed hypertension, diabetes mellitus, and hyperlipidemia were not associated with

22 events. Plasma fatty acids and oxylipins were analyzed with gas chromatography and HPLC-

$23 \mathrm{MS} / \mathrm{MS}$, respectively. None of 24 fatty acids quantified were associated with events. In contrast,

2439 plasma oxylipins were quantified and 8 were significantly associated with events. These 8

25 oxylipins are known regulators of vascular tone. For example, every 1 unit increase in

26 Thromboxane $\mathrm{B}_{2} /$ Prostaglandin $\mathrm{F}_{1 \alpha}$ and every $1 \mathrm{nM}$ increase in plasma 16-

27 hydroxyeicosatetraenoic acid, thromboxane $\mathrm{B}_{2}$, or 11,12-dihydroxyeicosatrienoic acid

28 (DiHETrE) increased the odds of having had $\geq 2$ events versus no event $(\mathrm{p}<0.05)$. The greatest

29 predictor was plasma 8,9-DiHETrE which increased the odds of acute coronary syndrome by $92-$

30 fold. In conclusion, specific oxylipins were highly associated with clinical events and may

31 represent specific biomarkers and/or therapeutic targets of cardiovascular disease.

32 Registered clinical trial: \#NCT00781950 at clinicaltrials.gov

33 Key Words: Lipidomics, Myocardial Infarction, Cerebrovascular Accident, Oxylipin, Fatty acid 
35 Abbreviations: 6 keto $=(6 \mathrm{k})$, acute coronary syndrome $=(\mathrm{ACS})$, cerebrovascular

36 accident=(CVA), dihommo gamma linolenic acid=(DGLA), dihydroxydocosapentanoic

37 acid=(DiHDPA), dihydroxyeicosatrienoic acid=(DiHETrE), dihydroxyoctadecenoic

38 acid=(DiHOME), HETrE=(hydroxyeicosatrienoic acid), hydroxydocosahexaenoic

39 acid,=(HDOHE), hydroxyeicosapentaenoic acid=(HEPE), hydroxyeicosatetraenoic

40 acid=(HETE), hydroxyeicosatrienoic acid=(HETrE), hydroxyoctadecadienoic acid=(HODE),

41 hydroxyoctadecatrienoic acid $=($ HOTrE $)$, oxooctadecadienoic acid $=($ OXOODE $)$,

42 prostaglandin $=(\mathrm{PG})$, standard error of the mean $=(\mathrm{SEM})$, transient ischemic attack $=(\mathrm{TIA})$,

43 trihydroxyoctadecenoic acid=(TriHOME), thromboxane $=($ TX $)$

44 
Introduction

Oxylipins are an intriguing group of molecules due to their ability to regulate

47 inflammation and vascular tone (Gabbs et al. 2015; Nishimaki and Seki 1999; Norris and Dennis 2014; Dennis and Norris 2015; Eskildsen et al. 2014). There are three oxylipin subclasses:

49 eicosanoids, octadecanoids and docosanoids. The eicosanoids are the most characterized in terms

50 of their physiological and pathophysiological effects. Due to recent advancements in detection

51 technology, many novel oxylipins within the octadecanoid and docosanoid subclasses have now

52 also been identified (Gabbs et al. 2015). The substrate of origin and often the enzyme that

53 produces these novel oxylipins are known, but the role for many of these molecules in

54 physiology and disease remains unclear. It is generalized that most omega 6 fatty acid-derived

55 oxylipins are more pro-inflammatory and vasoconstrictive than those produced from omega 3

56 fatty acids (Gabbs et al. 2015). Changes in vascular tone and inflammation have been implicated

57 in endothelial dysfunction, hypertension, and atherosclerosis. These processes play a

58 fundamental role in the etiology and progression of both cerebrovascular accidents and

59 myocardial infarction (Puddu et al. 2000; Montezano and Touyz 2012; Shearer and Newman

60 2009). It is plausible, therefore, that plasma oxylipins may act as significant mediators in the

61 progression of these events.

A patient population that is at a high risk for cardiovascular and cerebrovascular events

63 are those living with peripheral artery disease (PAD). PAD is defined as chronic arterial

64 occlusion typically from atherosclerosis to the arteries exclusive of intracranial and coronary

65 circulation, ie: typically in the arms and legs (Ouriel 2001). However, patients with PAD often

66 progress to coronary artery disease or cerebrovascular disease. PAD patients have a high

67 incidence of hypertension and hypertension is a particularly dangerous risk factor for 
cardiovascular outcomes (Caligiuri et al. 2016). Patients with PAD have a 35\% lower survival

69 rate and a higher incidence of myocardial infarctions and cerebrovascular accidents than matched

70 patients with coronary artery disease alone (Welton et al. 2008). For this reason, a patient

71 population living with PAD was chosen for the current investigation. The hypothesis of the

72 current study was novel eicosanoids derived from omega-6 fatty acids will increase the odds of

73 cardiovascular and cerebrovascular events in patients with PAD. In order to assess this

74 hypothesis, the prevalence of stable angina, acute coronary syndrome, transient ischemic attacks

75 and cerebrovacular accidents in patients living with PAD were assessed with regard to their

76 relationship to coventional risk factors, plasma fatty acid and oxylipin concentrations.

\section{Material and Methods}

Baseline data from patients enrolled in the randomized, double-blinded, placebo controlled FlaxPAD trial (\#NCT00781950 at clinicaltrials.gov) were included in this analysis

80 (Rodriguez-Leyva et al. 2013). The trial was approved and in accordance with the University of

81 Manitoba Research Ethics Boards, Health Canada Natural Health Product Directorate, and the

82 St. Boniface Hospital Research Review Committee. All participants provided written consent.

83 The total sample size for the current study was 98 participants ( $\mathrm{n}=25$ females and $n=73$ males).

84 Further details of the patient population and CONSORT flow diagram have been published

85 elsewhere (Rodriguez-Leyva et al. 2013; Caligiuri et al. 2014).

86

\section{Lididomics}

Plasma fatty acids were detected and quantified using gas chromatography and indicated as ng/mL. Details of methodology for fatty acid extraction and quantification are as previously described (Caligiuri et al. 2013). An expansive lipidomics analysis searching for over 100 
90 mediators were included in this study. Plasma oxylipins were extracted, detected, and quantified

91 as previously described (Caligiuri et al. 2014). Oxylipins are represented as nM.

92 Cardiovascular Events

Accurate coronary syndrome (ACS) was defined by S-T elevation myocardial infarction,

94 non S-T Elevation myocardial infarction, and unstable angina. These were defined according to

95 the Third Universal definition (Thygesen et al. 2012). ACS was defined by detecting a change of

96 cardiac biomarkers with one biomarker greater than the $99^{\text {th }}$ percentile upper reference limit in

97 addition to a minimum of one of the following: ischemic symptoms, new ST changes, new left

98 bundle branch block, pathological Q waves, new loss of healthy myocardium, left ventricular

99 wall abnomality, and/or intracoronary thrombus (Thygesen et al. 2012). Stable angina pectoris

100 was defined as symptoms of chest discomfort without elevated cardiac biomarkers or evidence of

101 other extraneous plausible causes (eg: gastroesophageal reflux) upon exertion (Thygesen et al.

102 2012). A cerebrovascular accident (CVA) was defined in accordance with the American Heart

103 Association and American Stroke Association guidelines and diagnosed with a computed

104 tomography scan or magnetic resonance imaging (Sacco et al. 2013). A transient ischemic attack

105 (TIA) was defined as an event without permanent cerebral damage but rather a brief period of

106 focal cerebral impedance of blood flow that resulted in temporary neurological dysfunction

107 (Easton et al. 2009).

108 Statistical Analysis

109 Statistical analyses were performed using SAS version 9.3 (Cary, NC, USA). Logistic

110 regression with score selection was utilized to determine the three most significantly associated

111 oxylipins or fatty acids with patient events. Univariate and multivariate forward selection logistic 
112 regression were utilized to determine the association of oxylipins and fatty acids to events while

113 controlling for hypertension, diabetes mellitus, hyperlipidemia, age, sex, smoking status and

114 medications. Bootstrap analysis was utilized for distribution estimation. Probability was assessed

115 with the logit (p) equation produced from the logistic regression analyses. The Wilcoxin-Rank

116 Sum test was utilized for 2 group comparisons due to the non-Gaussian distribution with a post-

117 hoc Bonferroni correction. All tests were set at a significance level of 0.05 .

118 Results

119 Prevalence of Cardiovascular and Cerebrovascular Events

120 Figure 1 illustrates the prevalence of cardiovascular and cerebrovascular events in the 121 study population. ACS affected the population studied here more than any other clinical event 122 ( $n=24$ patients). No patients presented with all 4 events. Four patients presented with 3 of the 4

123 possible events, 17 patients had 2 events, 20 patients presented with 1 event, and 57 patients had

124 no cardiovascular or cerebrovascular event.

125 Plasma Fatty Acid Concentrations by Presence of Event

126 Because polyunsaturated fatty acids are the substrates to the bioactive oxylipins, plasma

127 fatty acid concentrations were compared by presence of event. Twenty-four plasma fatty acids

128 were detected. Twleve of these were polyunsaturated fatty acids. Plasma fatty acid

129 concentrations $(\mathrm{ng} / \mathrm{mL})$ did not differ significantly among patients for presence of angina, ACS,

130 TIA or CVA (Online Supplementary Table 1), nor were plasma fatty acids significant predictors

131 of events in logistic regression models.

132 Plasma Oxylipin Concentrations by Presence of Event 
Thirty-nine plasma oxylipins were quantified in the current study population living with

134 peripheral artery disease. Concentrations are presented in Supplemental Table 2. Using the

135 Wilcoxin-Rank sum test followed by a Bonferroni correction, four plasma oxylipins were

136 significantly different between the presence of an event or absence (Figure 2). For example,

137 plasma 16-hydroxyeicosatetraenoic acid (HETE) was more than 4 times higher in patients that

138 suffered from a CVA versus patients that did not (Figure 2). Using the score selection method of

139 logistic regression, the oxylipins most significantly associated with an event were identified

140 (Tables 1-4). For example, only 6 keto (6k)-PGF ${ }_{1 \alpha}$ resulted in an odds ratio less than 1 for the

141 prevalence of TIAs, indicating a protective effect (Table 3). This contributed to the ratio of

$142 \mathrm{TXB}_{2} / 6 \mathrm{kPGF}_{1 \alpha}$ significantly increasing the odds of a TIA by 3.8 -fold for every 1 unit increase

143 (Table 3).

144 It was important to take into account the physiological concentrations of the plasma

145 oxylipins, as logistic regression is per $1 \mathrm{nM}$ increase. Therefore, Figure 3 illustrates the

146 probability of an event by plasma oxylipin concentration observed in the current population

$147(p<0.05) .16-H E T E$ resulted in the greatest increase in the probability of angina and

148 cerebrovascular accidents based on the observed physiological concentration range (Figure 3).

149 However, 8,9-DiHETrE had the largest slope at 4.53 (as indicated by $\mathrm{b}$ in the $\mathrm{y}=\mathrm{a}+\mathrm{bx}$

150 equation) for prediction of ACS prevalence.

151 Plasma oxylipin profiles were also compared between those with multiple events and

152 those with no event. 16-HETE (OR: $16.1(14.9,17.3))$, thromboxane $\mathrm{B}_{2}(\mathrm{OR}: 10.5(9.77,11.3)$ ),

153 and 11,12-DiHETrE (OR: $10.1(9.52,10.7)$ ), all increased the odds of having had multiple events

154 (ie: 2 or 3 events) versus no events. $\beta$-blockers were significantly associated with the prevalence

155 of angina, ACS and TIAs but not CVAs. Age, sex, smoking status, hyperlipidemia, hypertension, 
156 diabetes mellitus, and other medications were not significantly associated with any event. In the

157 presence of these factors, 16-HETE and 8,9-DiHETrE, still significantly influenced the odds of 158 events (Tables $1-4)$.

The ratio of $\mathrm{TXB}_{2}$ to $6 \mathrm{kPGF}_{1 \alpha}$ has previously held predictive value for cardiovascular

160 disease and therefore was assessed as a predictor of events in this population (Nishimaki and

161 Seki 1999; de Leval et al. 2004). $\mathrm{TXB}_{2} / 6 \mathrm{kPGF}_{1 \alpha}$ increased the odds of a TIA with an odds ratio

162 of $3.79(3.66,3.93$; $\mathrm{p}$-value $=0.019)$ as well as having multiple events (ie: 2 or 3 events) versus

163 no event OR: $5.13(4.90,5.36$; p-value =0.024). Adding all four DiHETrEs together provided

164 predictive value for having any event OR: $2.0(2.0,2.1)$ p-value $=0.034$ as well as an ACS OR:

$1651.95(1.05,3.64) \mathrm{p}$-value $=0.035$. Adding the concentration of HETEs held no predictive value

166 for events. Likewise, summation of the oxylipins by their respective enzyme (cyclooxygenase,

167 lipoxygenase, and cytochrome P450) held no predictive value.

168 Logistic regression was also performed comparing patients with only one event, as

169 indicated in Figure 1, versus the rest of the population without that particular event. Because this

170 decreased the number of cases to less than 10, this reflected an exploratory analysis only. In

171 these assessments, every $1 \mathrm{nM}$ increase in plasma 8,9-DiHETrE increased the odds of an ACS by

172 454-fold $(377,547)$ with a p-value of 0.041 . Every $1 \mathrm{nM}$ increase of plasma 16-HETE increased

173 the odds of a CVA by 25 -fold $(22,27)$ with a p-value of 0.043 . There were no significant

174 predictors for angina or TIA in these exploratory models.

175 Discussion

176 Oxylipins may have a role in cardiovascular and cerebrovascular events because of their

177 actions on inflammation and vascular tone (Norris and Dennis 2014; Dennis and Norris 2015). 
178 Patients with PAD are at a higher risk for cardiovascular events versus a healthy population or 179 even patients with coronary artery disease (Welton et al. 2008). For this reason, patients with 180 PAD presented an important population to investigate. In this population, typical risk factors 181 such as hypertension, diabetes, and hyperlipidemia did not influence the risk of events. This 182 could be due to the fact that hypertension, hyperlipidemia, and diabetes mellitus were well 183 controlled in the population. Despite this, the oxylipins which are markers for vascular tone and 184 inflammation were significantly associated to events. Oxylipins may present a new era of risk 185 markers/therapeutic targets particulary in the presence of well controlled risk factors.

This is the first study to observe the relationship of cardiovascular/cerebrovascular events

187 to a comprehensive plasma lipidomics profile in patients with PAD. There was no significant 188 relationship between fatty acid profiles and cardiovascular events; however their products, 189 plasma oxylipins, did significantly influence the presence of events. A similar observation was 190 observed in an obese animal model provided diets of varying fatty acid levels. Particular renal 191 phospholipid and triglyceride fatty acid concentrations did not differ among groups but renal 192 oxylipins significantly differed (Caligiuri et al. 2013; Caligiuri et al. 2014b). Similarly in the 193 current study, patients with past clinical events did not have significantly different concentrations 194 of omega- 6 fatty acids versus patients with no events. However, patients with events did have 195 significantly higher concentrations of many pro-inflammatory and vasoconstrictive oxylipins 196 produced from omega 6 fatty acids. In contrast, one omega- 6 derived oxylipin, $6 \mathrm{kPGF}_{1 \alpha}$, had a 197 protective odds ratio of 0.066 against transient ischemic attacks. $6 \mathrm{kPGF}_{1 \alpha}$ is the stable product of 198 prostacyclin $\left(\mathrm{PGI}_{2}\right)$, which is an anti-aggregatory, endothelial-derived vasodilator (Chen et al. 199 2002). $\mathrm{PGI}_{2}$ counteracts the aggregatory and vasoconstrictive effects of thromboxane $\mathrm{A}_{2}$ (Chen 
et al. 2002). This was supported by our finding that the ratio of $\mathrm{TXB}_{2}$ to $6 \mathrm{KPGF}_{1 \alpha}$ held predictive

201 value for patients having multiple events or a TIA alone.

16-HETE, thromboxane $\mathrm{B}_{2}$ and 11,12-DiHETrE are all produced from arachidonic acid and all significantly increased the odds of having had multiple cardiovascular events versus no

204 events. 16-HETE is produced by polymorphonuclear leukocytes in vitro (Bednar et al. 2000) and is released upon angiotensin II stimulation which may explain its positive relationship to CVAs and angina. 16-HETE is released following angiotensin II stimulation. However, there was no statistically significant correlation between ACE inhibitors and cardiovascular events. This dilemma may be explained in several ways. First, ACE inhibitors were trending to be statistically significant $(\mathrm{p}=0.12)($ Table 4$)$ but insufficient sample size may have limited the capacity to

210 power these results to statistical significance. In addition, we have no data on patient adherence

211 to ACE inhibitors. Furthermore, although 16-HETE is released in response to Angiotensin II,

212 how an ACE inhibitor may impact 16-HETE concentrations in patients is unknown. An ACE

213 inhibitor may not necessarily prevent 16-HETE release. The production of 16-HETE is regulated

214 by many means including the concentration of other HETEs, CYP450, and arachidonic acid

215 availability. It is also unclear if other medications concomitantly administered to these patients

216 may have had additional and perhaps contrasting effects on plasma 16-HETE concentrations.

217 The exact mechanism for the relationship with cardiovascular events has yet to be determined

218 and represents an intriguing area for future research. Less surprising was the positive

219 relationship of $\mathrm{TXB}_{2}$ with events because $\mathrm{TXB}_{2}$ is the stable product of the potent

220 vasoconstrictor thromboxane $A_{2}$. Similarly, thromboxane $B_{2}$ is present in significantly higher

221 concentrations in the coronary circulation in patients with angina versus healthy subjects and

222 during times of chest pain versus no pain (Tada et al. 1981). 11,12-DiHETrE is a product of 
223 11,12-epoxyeicosatrienoic acid (EpETrE). When 11,12-EpETrE is converted by soluble epoxide

224 hydrolase to 11,12-DiHETrE, it causes a significant loss of vasodilation (Sudhahar et al. 2010;

225 Falk et al. 2003). Therefore, higher concentrations of 11,12-DiHETrE have been implicated in

226 vasoconstriction and even hypertension (Caligiuri et al. 2014). It may be precisely the vascular

227 constricting properties of 11,12-DiHETrE that explain the increased odds of events in the present

228 study. The positive relationship of plasma 18-HEPE to ACS was unexpected. 18-HEPE is a pre-

229 cursor to the E-series resolvins which regulate resolution of inflammation and, therefore, are

230 generalized as protective (Oh et al. 2011; Serhan and Petasis 2011). It is possible that following

231 ACS, plasma 18-HEPE levels increase as a protective adaptive mechanism to reduce

232 inflammation. Future research is required to determine if 18-HEPE can improve cardiac

233 remodelling post-MI. Other oxylipins may not have been associated with cardiovascular

234 outcomes due to a lack of affect in vascular tone regulation, or they may have a very short half-

235 life, or they may have concentrations that are too variable in the population of 98 patients.

It is also important to note that the largest slopes in the probability analysis shown in

237 Figure 3 belonged to 8,9-DiHETrE and 16-HETE. This indicates that the odds of events changed

238 more significantly with smaller changes in the plasma concentration of these two oxylipins

239 versus other oxylipins. 8,9-DiHETrE and 16-HETE were also significant predictors of ACS and

240 CVAs, respectively, in the multivariate logistic regression as well as the exploratory analysis of

241 patients with only one event. As a result, these two molecules may prove to be particularly

242 powerful targets for therapeutic investigation or risk marker assessment of ACS and CVAs in the

243 future.

The relationship of $\beta$-blockers to events was significant for angina, ACS, and TIAs. $\beta$ -

245 blockers are a first-line therapy for hypertension and angina, and are often prescribed to prevent 
246 a secondary myocardial infarction (Bradley et al. 2007). In this patient population, $\beta$-blockers

247 were prescribed for anginal symptoms more often than calcium channel blockers, thus explaining

248 the lack of a significant relationship of calcium channel blockers to angina. For these reasons, it

249 likely explains the relationship between this class of medications and events.

250 262 immediately after an event.

\section{Conclusion}

\section{Limitations}

It is important to note that limitations exist within this study. First, because oxylipins were elevated in patients following an event, it is diffcult to ascertain if they are a cause or a consequence of the event. Because of their physiological role (ie: vasoconstricting or inflammatory), it is reasonable to propose that either or both roles are valid. Secondly, the length of time from the clinical event to the measurement of the oxylipins in this study was variable and may have influenced the oxylipin concentrations. Third, information regarding the type of CVA or ACS and the diagnostic method to detect the events was not standardized in the medical records used. Lastly, the distribution of sex was skewed toward males. Future trials in a different population of hypertensive patients should aim to recruit a more even sex distribution to obtain data with high power for both sexes. Future prospective studies following a large cohort of at risk patients may resolve these questions by obtaining plasma oxylipin profiles prior to and

In conclusion, this research supports a significant relationship for specific plasma oxylipins such as 16-HETE and 8,9-DiHETrE to cardiovascular and cerebrovascular events in the presence of well controlled risk factors. Oxylipins may have the potential to serve as new risk markers/therapeutic targets beyond conventional standard of care practice. This was not a 
14

268 phenomenon generalized to all lipids as plasma fatty acid concentrations were not associated

269 with events in the current study. It is important to note that the oxylipin concentrations observed

270 here may increase the risk of a clinical event or be important mediators in the healing process

271 following an event. This study has identified specific oxylipins that are attractive targets to

272 investigate for their involvement in cardiovascular and cerebrovascular events. Therefore, these

273 oxylipins may be used as targets in future clinical or experimental investigations utilizing a

274 lipidomics approach. 


\section{Funding Sources}

276 Canadian Institutes of Health Research, Flax 2015, Agri-Food Research Development

277 Initiative, Western Grains Research Foundation provided grants that supported this work. St.

278 Boniface Hospital Foundation provided infrastrucutral support. Stephanie Caligiuri was funded

279 by the Canadian Institutes of Health Research Patient Oriented Research Doctoral Scholarship

280 and a Research Manitoba Doctoral Scholarship.

\section{Disclosures}

$282 \quad$ None.


Austria, J.A., Richard, M.N., Chahine, M.N., Edel, A.L., Malcolmson, L.J., Dupasquier, C.M., et

al. Bioavailability of alpha-linolenic acid in subjects after ingestion of three different forms of flaxseed. J. Am. Coll. Nutr. 2008;27:214-21.

Bednar, M.M., Gross, C.E., Balazy, M.K., Belosludtsev, Y., Colella, D.T., Falck, J.R., et al.

289 16(R)-hydroxy-5,8,11,14-eicosatetraenoic acid, a new arachidonate metabolite in human

290 polymorphonuclear leukocytes. Biochem. Pharmacol.2000;60:447-55.

291 Bradley, E.H., Herrin, J., Mattera, J.A., Holmboe, E.S., Wang, Y., Frederick, P., et al. Quality

292 improvement efforts and hospital performance: Rates of beta-blocker prescription after acute

293 myocardial infarction. Med. Care. 2005;43:282-92.

294 Caligiuri,S.P., Aukema, H.M., Ravandi, A., Guzman, R., Dibrov, E., Pierce G.N. Flaxseed

295 consumption reduces blood pressure in patients with hypertension by altering circulating

296 oxylipins via an alpha-linolenic acid-induced inhibition of soluble epoxide hydrolase.

297 Hypertension. 2014;64:53-59.

298 Caligiuri, S.P.B., Austria, J.A., and Pierce, G.N. Alarming prevalence of emergency

299 hypertension levels in the general public identified by a hypertension awareness campaign. Am.

$300 \quad$ J. Hypertension 2016; in press.

301 Caligiuri, S.P., Love, K., Winter, T., Gauthier, J., Taylor, C.G., Blydt-Hansen, T., et al. Dietary

302 linoleic acid and alpha-linolenic acid differentially affect renal oxylipins and phospholipid fatty

303 acids in diet-induced obese rats. J. Nutr. 2013;143:1421-31. 
304 Caligiuri, S.P., Blydt-Hansen, T., Love, K., Grégoire, M., Taylor, C.G., Zahradka, P., et al.

305 Evidence for the use of glomerulomegaly as a surrogate marker of glomerular damage and for

306 alpha-linolenic acid-rich oils in the treatment of early obesity-related glomerulopathy in a diet-

307 induced rodent model of obesity. Appl. Physiol. Nutr. Metab. 2014 Aug;39(8):951-9.

308 Cheng, Y., Austin, S.C., Rocca, B., Koller, B.H., Coffman, T.M., Grosser, T., et al. Role of

309 prostacyclin in the cardiovascular response to thromboxane A2. Science. 2002;296:539-41.

310 Danaei, G., Ding, E.L., Mozaffarian, D., Taylor, B., Rehm, J., Murray, C.J., et al. The

311 preventable causes of death in the united states: Comparative risk assessment of dietary, lifestyle,

312 and metabolic risk factors. PLoS Med. 2009;6:e1000058.

313 de Leval, X., Hanson, J., David, J.L., Masereel, B., Pirotte, B., and Dogné, J.M. New

314 developments on thromboxane and prostacyclin modulators part II: Prostacyclin modulators.

315 Curr. Med. Chem. 2004;11:1243-52.

316 Dennis, E.A., and Norris, P.C. Eicosanoid storm in infection and inflammation. Nat.Rev.

317 Immunol. 2015;15:511-23.

318 Easton, J.D., Saver, J.L., Albers, G.W., Alberts, M.J., Chaturvedi, S., Feldmann, E., et al.

319 Definition and evaluation of transient ischemic attack: A scientific statement for healthcare

320 professionals from the american heart Association/American stroke association stroke council;

321 council on cardiovascular surgery and anesthesia; council on cardiovascular radiology and

322 intervention; council on cardiovascular nursing; and the interdisciplinary council on peripheral

323 vascular disease. Stroke. 2009;40:2276-93. 
324 Eskildsen, M.P., Hansen, P.B., Stubbe, J., Toft, A., Walter, S., Marcussen, N., et al.

325 Prostaglandin I2 and prostaglandin E2 modulate human intrarenal artery contractility through

326 prostaglandin E2-EP4, prostacyclin-IP, and thromboxane A2-TP receptors. Hypertension.

$327 \quad 2014 ; 64: 551-6$.

328 Falck, J.R., Krishna, U.M., Reddy, Y.K., Kumar, P.S., Reddy, K.M., Hittner, S.B., et al.

329 Comparison of vasodilatory properties of 14,15-EET analogs: Structural requirements for

330 dilation. Am. J. Physiol. Heart Circ. Physiol. 2003;284:H337-49.

331 Gabbs, M., Leng, S., Devassy, J.G., Monirujjaman, M., and Aukema, H.M. Advances in our

332 understanding of oxylipins derived from dietary PUFAs. Adv. Nutr. 2015;6:513-40.

333 Montezano, A.C., and Touyz, R.M. Molecular mechanisms of Hypertension-Reactive oxygen

334 species and antioxidants: A basic science update for the clinician. Can. J.Cardiol. 2012;28:28833595.

336 Nishimaki, S., and Seki, K. An imbalance between prostacyclin and thromboxane in relation to

337 cerebral blood flow in neonates with maternal preeclampsia. Prostaglandins Other Lipid Mediat.

$338 \quad 1999 ; 58: 43-9$.

339 Norris, P.C., and Dennis E.A. A lipidomic perspective on inflammatory macrophage eicosanoid 340 signaling. Adv. Bio.1 Regul. 2014;54:99-110.

341 Oh, S.F., Pillai, P.S., Recchiuti, A., Yang, R., and Serhan, C.N. Pro-resolving actions and

342 stereoselective biosynthesis of $18 \mathrm{~S}$ E-series resolvins in human leukocytes and murine

343 inflammation. J. Clin. Invest. 2011;121:569-81.

344 Ouriel, K. Peripheral arterial disease. Lancet. 2001;358:1257-64. 
345 Puddu, P., Puddu, G.M., Zaca, F., and Muscari, A. Endothelial dysfunction in hypertension. Acta 346 Cardiol. 2000;55:221-32.

347 Rodriguez-Leyva, D., Weighell, W., Edel, A.L., LaVallee, R., Dibrov, E., Pinneker, R., et al. 348 Potent antihypertensive action of dietary flaxseed in hypertensive patients. Hypertension. $349 \quad 2013 ; 62: 1081-1089$.

350 Sacco, R.L., Kasner, S.E., Broderick, J.P., Caplan, L.R., Connors, J.J., Culebras, A., et al. An 351 updated definition of stroke for the 21st century: A statement for healthcare professionals from 352 the american heart Association/American stroke association. Stroke. 2013;44:2064-89.

353 Serhan, C.N., and Petasis, N.A. Resolvins and protectins in inflammation resolution. Chem Rev. $354 \quad 2011 ; 111: 5922-43$

355 Shearer, G.C., and Newman, J.W. Impact of circulating esterified eicosanoids and other 356 oxylipins on endothelial function. Curr Atheroscler Rep. 2009;11:403-10.

357 Sudhahar, V., Shaw,S., and Imig, J.D. Epoxyeicosatrienoic acid analogs and vascular function. 358 Curr Med Chem. 2010;17:1181-90.

359 Tada, M., Kuzuya, T., Inoue, M., Kodama, K., Mishima, M., Yamada, M., et al. Elevation of 360 thromboxane B2 levels in patients with classic and variant angina pectoris. Circulation.

$361 \quad 1981 ; 64: 1107-15$.

362 Thygesen, K., Alpert, J.S., Jaffe, A.S., Simoons, M.L., Chaitman, B.R., and White, H.D. Third 363 universal definition of myocardial infarction. Circulation. 2012;126:2020-35. 
20

364 Welten, G.M., Schouten, O., Hoeks, S.E., Chonchol, M., Vidakovic, R., van Domburg, R.T., et

365 al. Long-term prognosis of patients with peripheral arterial disease: A comparison in patients

366 with coronary artery disease. J. Am. Coll. Cardiol. 2008;51:1588-96.

367 


\section{Figure Legends}

369 Figure 1: Venn Diagram of Cardiovascular and Cerebrovascular Event Prevalence in 98 Patients

370 With Peripheral Artery Disease

371 Figure 2: Concentration of Plasma Oxylipins by Presence of Cardiovascular/Cerebrovascular

372 Outcomes * denotes p-value $<0.05$. Abbreviations: 6-keto=(6k), acute coronary

373 syndrome $=($ ACS $)$, cerebrovacular accident $=($ CVA $)$, dihydroxyeicosatrienoic acid $=(\mathrm{DiHETrE})$,

374 hydroxyeicosatetranoic acid=(HETE), prostaglandin= $(\mathrm{PG})$, transient ischemic attack=(TIA),

375 thromboxane $=(\mathrm{TX})$.

376 Figure 3: Probability of Cardiovascular and Cerebrovascular Events by Plasma Oxylipin

377 Concentrations (nM). Oxylipins were selected based on the score selection method of logistic

378 regression to determine the strongest predicting oxylipins. Probabilities were obtained by taking

379 the EXP of logit (p) to first obtain the odds. Probability was calculated by odds/(1+odds).

380 Abbreviations: 6-keto=(6k), dihydroxyeicosatrienoic acid=(DiHETrE), hydroxyeicosapentanoic

381 acid=(HEPE), hydroxyeicosatetranoic acid=(HETE), prostaglandin $=(\mathrm{PG})$, thromboxane $=(\mathrm{TX})$. 
383 Table 1: Univariate and Multivariate Logistic Regression Models for the Risk Assessment of

384 Stable Angina

\begin{tabular}{lcccccc}
\hline Variable & Cases & Controls & Univariate & p-value & Multivariate & p-value \\
& & & OR $(95 \% \mathrm{CI})$ & & OR $(95 \% \mathrm{CI})$ & \\
& & & & & & \\
\hline Plasma Oxylipin & 39 & $\mathrm{~N} / \mathrm{A}$ & & & & \\
PGE $_{2}$ & & & $80(71,90)$ & 0.022 & $80(71,90)$ & 0.022 \\
16-HETE & & $9.1(8.5,9.7)$ & 0.025 & &
\end{tabular}

Other Characteristics

$\begin{array}{lcccc}\text { Age } \geq 65 \text { years } & 65 & 33 & 1.8(0.54,6.2) & 0.33 \\ \text { Female Sex } & 25 & 73 & 0.63(0.16,2.4) & 0.50 \\ \text { Smoking Status(current) } & 25 & 73 & 0.40(0.083,1.9) & 0.24 \\ \text { Hypertension } & 74 & 24 & 2.2(0.47,11) & 0.31 \\ \text { Diabetes Mellitus } & 33 & 65 & 1.9(0.62,5.8) & 0.27 \\ \text { Hyperlipidemia } & 78 & 20 & 3.9(0.49,32) & 0.20\end{array}$

Medications

$\begin{array}{lcccc}\text { Beta Blocker } & 33 & 65 & 3.1(1.0,9.3) & 0.043 \\ \text { CCB } & 27 & 71 & 0.33(0.07,1.5) & 0.16 \\ \text { ACE inhibitor } & 47 & 51 & 1.6(0.56,4.8) & 0.37 \\ \text { ARB } & 15 & 83 & 1.4(0.33,5.4) & 0.68 \\ \text { Diuretic } & 39 & 39 & 0.89(0.30,2.7) & 0.84 \\ \text { Aspirin } & 71 & 27 & 0.65(0.21,2.0) & 0.45 \\ \text { Statin } & 70 & 28 & 2.5(0.52,12) & 0.26\end{array}$

385 Angiotensin Converting Enzyme= $(\mathrm{ACE})$, Angiotensin Receptor Blocker= $(\mathrm{ARB})$, Calcium

386 Channel Blocker $=(\mathrm{CCB})$, Hydroxyeicosatetraenoic acid= $($ HETE $)$, Prostaglandin $=(\mathrm{PG})$ 
387 Table 2 : Univariate and Multivariate Logistic Regression Models for the Risk Assessment of 388 Acute Coronary Syndrome

\begin{tabular}{|c|c|c|c|c|c|c|}
\hline Variable & Cases & Controls & $\begin{array}{l}\text { Univariate } \\
\text { OR }(95 \% \mathrm{CI})\end{array}$ & p-value & $\begin{array}{l}\text { Multivariate } \\
\text { OR }(95 \% \mathrm{CI})\end{array}$ & p-value \\
\hline Plasma Oxylipin & 39 & $\mathrm{~N} / \mathrm{A}$ & & & & \\
\hline 8,9-DiHETrE & & & $92.4(82.0,104)$ & 0.0192 & $92.4(82.0,104)$ & 0.0192 \\
\hline 18-HEPE & & & $4.1(4.0,4.3)$ & 0.045 & & \\
\hline \multicolumn{7}{|l|}{ Other Characteristics } \\
\hline Age $\geq 65$ years & 65 & 33 & $1.1(0.44,3.0)$ & 0.78 & & \\
\hline Female Sex & 25 & 73 & $0.71(0.23,2.2)$ & 0.55 & & \\
\hline Smoking Status(current) & 25 & 73 & $1.0(0.35,3.0)$ & 0.97 & & \\
\hline Hypertension & 74 & 24 & $4.4(0.96,21)$ & 0.057 & & \\
\hline Diabetes & 33 & 65 & $1.6(0.60,4.0)$ & 0.36 & & \\
\hline Hyperlipidemia & 78 & 20 & $2.0(0.52,7.4)$ & 0.32 & & \\
\hline \multicolumn{7}{|l|}{ Medications } \\
\hline Beta Blocker & 33 & 65 & $8.8(3.1,25)$ & $<0.00010$ & $12(3.6,40)$ & $<0.0001$ \\
\hline $\mathrm{CCB}$ & 27 & 71 & $0.44(0.14,1.4)$ & 0.18 & & \\
\hline ACE inhibitor & 47 & 51 & $1.6(0.62,3.9)$ & 0.35 & & \\
\hline ARB & 15 & 83 & $0.43(0.090,2.0)$ & 0.29 & & \\
\hline Diuretic & 39 & 39 & $1.7(0.69,4.4)$ & 0.24 & & \\
\hline Aspirin & 71 & 27 & $0.62(0.23,1.6)$ & 0.33 & & \\
\hline Statin & 70 & 28 & $3.1(0.82,11)$ & 0.094 & & \\
\hline
\end{tabular}

389 Angiotensin Converting Enzyme $=(\mathrm{ACE})$, Angiotensin Receptor Blocker $=(\mathrm{ARB})$, Calcium

390 Channel Blocker=(CCB), Dihydroxyeicosatrienoic acid=(DiHETrE), Hydroxyeicosapentanoic 391 acid=(HEPE) 
392 Table 3: Univariate and Multivariate Logistic Regression Models for the Risk Assessment of 393 Transient Ischemic Attacks

\begin{tabular}{|c|c|c|c|c|}
\hline Variable & Cases & Controls & $\begin{array}{l}\text { Univariate } \\
\text { OR }(95 \% \mathrm{CI})\end{array}$ & $\mathrm{p}-$ \\
\hline Plasma Oxylipin & 39 & $\mathrm{~N} / \mathrm{A}$ & & \\
\hline $\mathrm{TXB}_{2} / 6 \mathrm{kPGF}_{1 \alpha}$ & & & $3.8(3.6,3.9)$ & 0.0 \\
\hline $6 \mathrm{kPGF}_{1 \alpha}$ & & & $0.066(0.061,0.072)$ & 0.0 \\
\hline \multicolumn{5}{|l|}{ Other Characteristics } \\
\hline Age $\geq 65$ years & 65 & 33 & $1.8(0.54,6.2)$ & 0.3 \\
\hline Female Sex & 25 & 73 & $0.37(0.077,1.7)$ & \\
\hline Smoking Status(current) & 25 & 73 & $0.36(0.076,1.7)$ & \\
\hline Hypertension & 74 & 24 & $1.3(0.33,5.0)$ & \\
\hline Diabetes & 33 & 65 & $0.96(0.30,3.1)$ & \\
\hline Hyperlipidemia & 78 & 20 & $0.97(0.24,3.8)$ & \\
\hline
\end{tabular}

Medications

$\begin{array}{lcccc}\text { Beta Blocker } & 33 & 65 & 3.1(1.0,9.3) & 0.043 \\ \text { CCB } & 27 & 71 & 1.7(0.57,5.4) & 0.33 \\ \text { ACE inhibitor } & 47 & 51 & 0.90(0.31,2.6) & 0.85 \\ \text { ARB } & 15 & 83 & 1.3(0.33,5.4) & 0.68 \\ \text { Diuretic } & 39 & 39 & 0.64(0.20,2.0) & 0.45 \\ \text { Aspirin } & 71 & 27 & 0.47(0.16,1.4) & 0.18 \\ \text { Statin } & 70 & 28 & 0.95(0.62,1.5) & 0.83\end{array}$

394 6-keto=(6k), Angiotensin Converting Enzyme=(ACE), Angiotensin Receptor Blocker=(ARB),

395 Calcium Channel Blocker $=(\mathrm{CCB})$, Prostagladin $=(\mathrm{PG})$, Thromboxane $=(\mathrm{TX})$ 
396 Table 4: Univariate and Multivariate Logistic Regression Models for the Risk Assessment of 397 Cerebrovascular Accidents

\begin{tabular}{|c|c|c|c|c|}
\hline Variable & Cases & Controls & $\begin{array}{l}\text { Univariate } \\
\text { OR }(95 \% \mathrm{CI})\end{array}$ & $\mathrm{p}$-va \\
\hline Plasma Oxylipin & 39 & $\mathrm{~N} / \mathrm{A}$ & & \\
\hline 16-HETE & & & $55(51,60)$ & 0.001 \\
\hline $\mathrm{PGF}_{2 \alpha}$ & & & $3.3(3.2,3.5)$ & 0.047 \\
\hline \multicolumn{5}{|l|}{ Other Characteristics } \\
\hline Age $\geq 65$ years & 65 & 33 & $0.33(0.86,1.3)$ & 0.10 \\
\hline Female Sex & 25 & 73 & $2.1(0.55,8.3)$ & 0.28 \\
\hline Smoking Status(current) & 25 & 73 & $0.81(0.16,4.2)$ & 0.80 \\
\hline Hypertension & 74 & 24 & $1.1(0.21,5.7)$ & 0.91 \\
\hline Diabetes & 33 & 65 & $0.97(0.23,4.1)$ & 0.96 \\
\hline Hyperlipidemia & 78 & 20 & $0.84(0.16,4.4)$ & 0.8 \\
\hline
\end{tabular}

Medications

$\begin{array}{lcccc}\text { Beta Blocker } & 33 & 65 & 1.4(0.36,5.2) & 0.66 \\ \text { CCB } & 27 & 71 & 0.63(0.13,3.2) & 0.58 \\ \text { ACE inhibitor } & 47 & 51 & 3.1(0.75,13) & 0.12 \\ \text { ARB } & 15 & 83 & <0.001(<0.001,>999) & 0.96 \\ \text { Diuretic } & 39 & 39 & 4.1(0.99,17) & 0.052 \\ \text { Aspirin } & 71 & 27 & 0.38(0.10,1.4) & 0.15 \\ \text { Statin } & 70 & 28 & 1.1(0.29,4.4) & 0.86\end{array}$

398 Angiotensin Converting Enzyme=(ACE), Angiotensin Receptor Blocker=(ARB), Calcium

399 Channel Blocker=(CCB), Hydroxyeicosatetraenoic acid=(HETE), Prostaglandin= $(\mathrm{PG})$ 


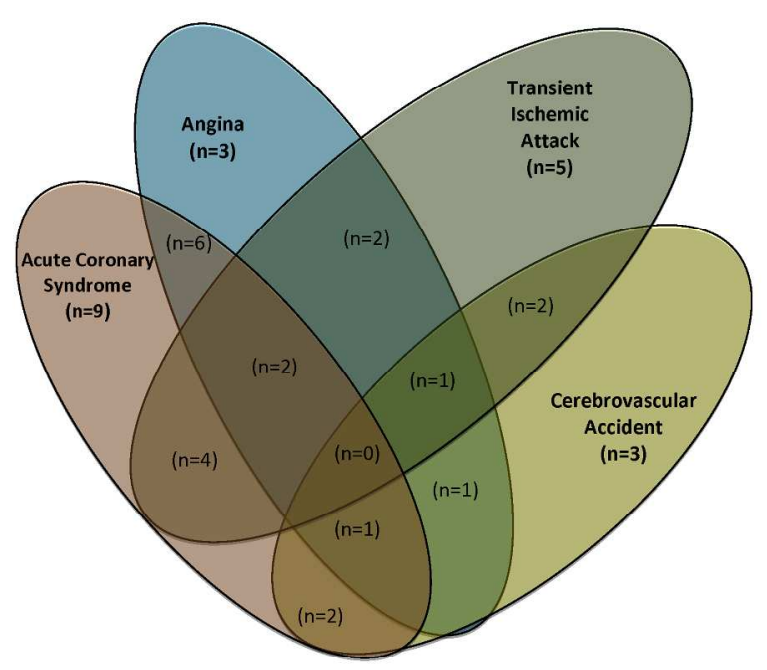

Figure 1: Venn Diagram of Cardiovascular and Cerebrovascular Event Prevalence in 98 Patients With Peripheral Arterial Disease

Figure 1

$215 \times 279 \mathrm{~mm}(300 \times 300 \mathrm{DPI})$

https://mc06.manuscriptcentral.com/cjpp-pubs 

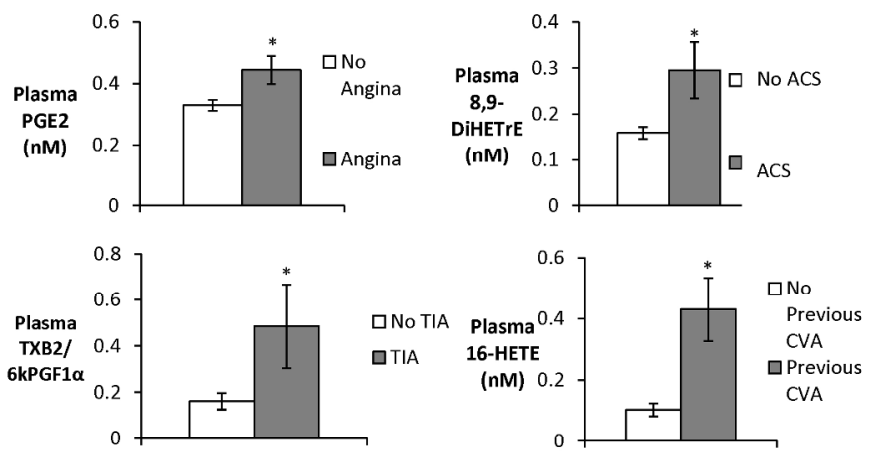

Figure 2: Concentration of Plasma Oxylipins by Presence of Cardiovascular/Cerebrovascular Outcomes * denotes p-value $<0.05$. Abbreviations: 6-keto (6k), acute coronary syndrome (ACS), cerebrovacular accident (CVA), dihydroxyeicosatrienoic acid (DiHETrE), hydroxyeicosatetranoic acid (HETE), prostaglandin (PG), transient ischemic attack (TIA), thromboxanc (TX).

Figure 2

$215 \times 279 \mathrm{~mm}(300 \times 300 \mathrm{DPI})$ 

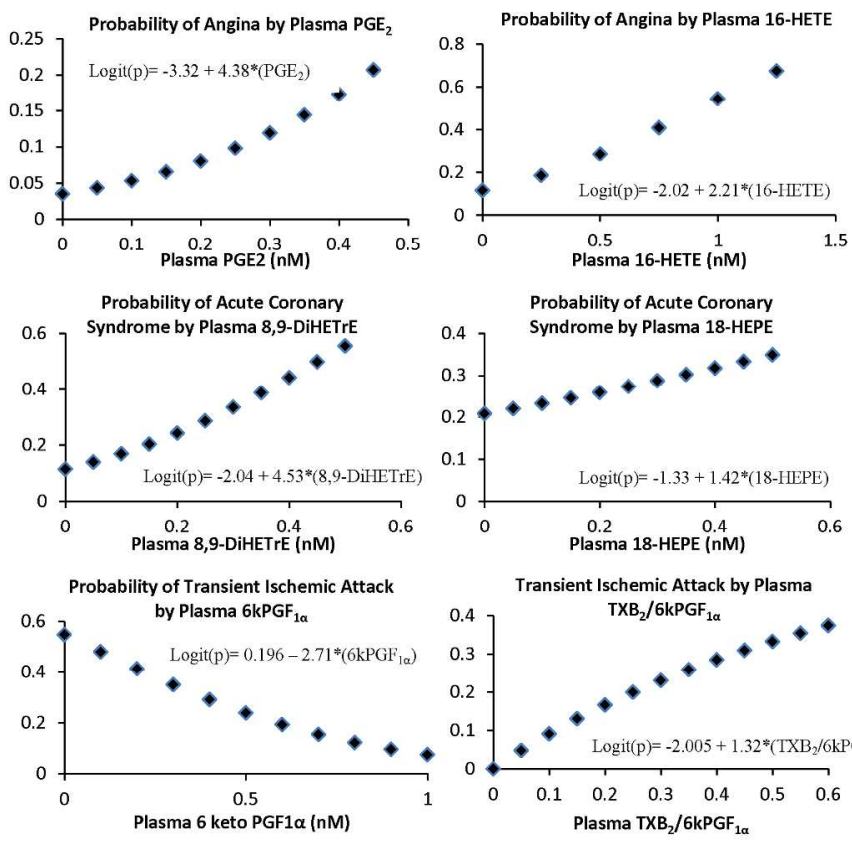

Transient Ischemic Attack by Plasm
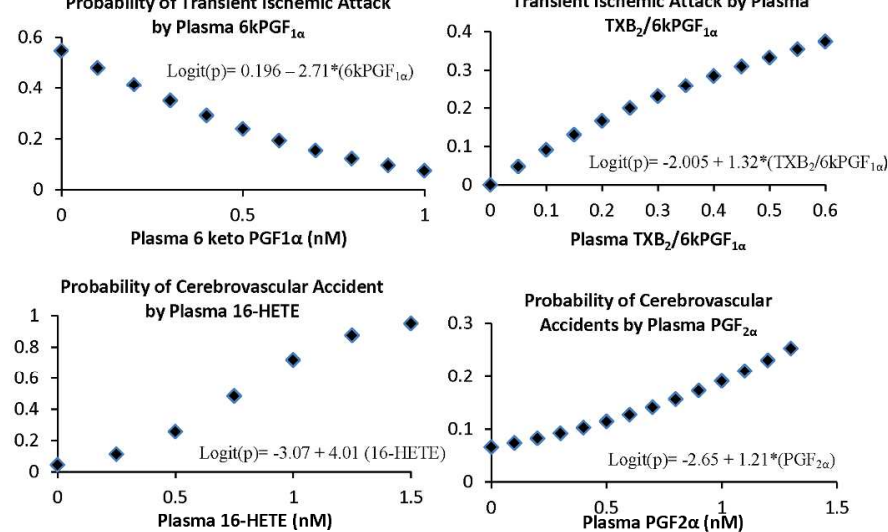

Figure 3: Probability of Cardiovascular and Cerebrovascular Events by Plasma Oxylipin Concentrations (nM). Oxylipins were selected based on the score selection method of logistic regression to determine the strongest predicting oxylipins. Probabilities were obtained by taking the EXP of logit (p) to first

Figure 3

$215 \times 279 \mathrm{~mm}(300 \times 300 \mathrm{DPI})$ 
Figure 3 continued

$215 \times 279 \mathrm{~mm}(300 \times 300 \mathrm{DPI})$ 
Supplemental Material

Table 1: Plasma Fatty Acid Concentration $(\mu \mathrm{g} / \mathrm{mL})$ by Presence of Event

\begin{tabular}{|c|c|c|c|c|c|c|c|c|}
\hline Fatty Acid & $\begin{array}{c}\text { No } \\
\text { Angina } \\
(\mathrm{n}=82)\end{array}$ & SEM & $\begin{array}{c}\text { Yes } \\
\text { Angina } \\
(n=16)\end{array}$ & SEM & $\begin{array}{c}\text { No ACS } \\
(\mathrm{n}=74)\end{array}$ & SEM & $\begin{array}{c}\text { Yes ACS } \\
(n=24)\end{array}$ & SEM \\
\hline $\mathrm{C} 12: 0$ & 0.7 & 0.3 & 0.3 & 0.3 & 0.5 & 0.3 & 1.0 & 0.6 \\
\hline C14:0 & 24.7 & 1.7 & 23.2 & 4.6 & 25.3 & 2.0 & 22.1 & 2.2 \\
\hline C14:1 & 1.7 & 0.3 & 1.5 & 0.8 & 1.5 & 0.3 & 2.0 & 0.7 \\
\hline $\mathrm{C} 16: 0$ & 640.6 & 25.9 & 578.8 & 65.0 & 642.6 & 29.1 & 593.2 & 40.6 \\
\hline C16:1 & 59.9 & 4.2 & 56.8 & 17.2 & 62.1 & 5.5 & 50.9 & 5.9 \\
\hline C18:0 & 189.0 & 5.4 & 170.7 & 12.7 & 188.0 & 5.9 & 179.7 & 9.4 \\
\hline C18:1 Oleic & 703.4 & 26.6 & 705.3 & 72.2 & 707.2 & 28.9 & 692.9 & 51.4 \\
\hline C18:1 Vaccenic & 45.9 & 1.7 & 44.5 & 5.6 & 46.7 & 2.0 & 42.6 & 3.2 \\
\hline C18:2 & 702.3 & 21.3 & 637.2 & 52.0 & 703.3 & 22.4 & 655.7 & 41.7 \\
\hline C20:0 & 5.5 & 0.3 & 4.4 & 0.8 & 5.6 & 0.3 & 4.7 & 0.6 \\
\hline C18:3 DGLA & 13.2 & 0.8 & 12.2 & 1.4 & 12.9 & 0.8 & 13.5 & 1.1 \\
\hline C20:1 & 3.4 & 0.3 & 4.0 & 0.7 & 3.6 & 0.3 & 3.2 & 0.5 \\
\hline C18:3 ALA & 18.2 & 1.2 & 22.9 & 4.1 & 18.4 & 1.2 & 20.7 & 3.0 \\
\hline C20:2 & 3.6 & 0.3 & 3.9 & 0.7 & 3.6 & 0.4 & 3.8 & 0.6 \\
\hline $\mathrm{C} 22: 0$ & 15.9 & 0.7 & 12.8 & 1.5 & 15.9 & 0.8 & 13.8 & 1.2 \\
\hline C20:3 & 36.5 & 1.4 & 33.4 & 3.7 & 36.8 & 1.5 & 33.3 & 2.4 \\
\hline C20:4 & 212.0 & 6.6 & 194.3 & 14.7 & 210.3 & 7.1 & 205.4 & 11.8 \\
\hline $\mathrm{C} 22: 2$ & 0.1 & 0.0 & 0.3 & 0.3 & 0.1 & 0.1 & 0.2 & 0.2 \\
\hline C24:0 & 11.9 & 0.5 & 9.2 & 1.1 & 11.9 & 0.5 & 10.3 & 0.8 \\
\hline C20:5 & 20.8 & 1.2 & 20.4 & 2.1 & 20.7 & 1.3 & 20.8 & 2.0 \\
\hline C24:1 & 24.2 & 0.8 & 22.1 & 2.9 & 24.4 & 0.9 & 22.3 & 1.9 \\
\hline C22:4 & 3.9 & 0.3 & 3.1 & 0.8 & 3.9 & 0.4 & 3.5 & 0.6 \\
\hline $\mathrm{C} 22: 5$ & 13.3 & 0.6 & 13.5 & 1.3 & 13.2 & 0.7 & 13.7 & 1.1 \\
\hline $\mathrm{C} 22: 6$ & 41.6 & 2.2 & 40.3 & 3.6 & 42.7 & 2.4 & 37.5 & 2.5 \\
\hline
\end{tabular}




\begin{tabular}{|c|c|c|c|c|c|c|c|c|}
\hline Fatty Acid & $\begin{array}{c}\text { No } \\
\text { TIA } \\
(\mathrm{n}=82) \\
\end{array}$ & SEM & $\begin{array}{c}\text { Yes } \\
\text { TIA } \\
(\mathrm{n}=16) \\
\end{array}$ & SEM & $\begin{array}{c}\text { No } \\
\text { CVA } \\
(\mathrm{n}=88) \\
\end{array}$ & SEM & $\begin{array}{c}\text { Yes } \\
\text { CVA } \\
(\mathrm{n}=10)\end{array}$ & SEM \\
\hline C12:0 & 0.7 & 0.3 & 0.3 & 0.3 & 0.6 & 0.3 & 0.7 & 0.5 \\
\hline C14:0 & 25.2 & 1.9 & 20.8 & 2.1 & 24.2 & 1.7 & 27.0 & 4.4 \\
\hline C14:1 & 1.8 & 0.3 & 0.9 & 0.5 & 1.6 & 0.3 & 1.7 & 0.9 \\
\hline C16:0 & 636.0 & 27.4 & 602.5 & 45.4 & 627.1 & 26.0 & 660.9 & 61.2 \\
\hline C16:1 & 60.9 & 5.1 & 51.6 & 7.9 & 58.8 & 4.8 & 64.7 & 11.8 \\
\hline C18:0 & 186.5 & 5.6 & 183.1 & 11.5 & 185.2 & 5.4 & 192.9 & 12.8 \\
\hline C18:1 Oleic & 705.6 & 27.8 & 693.7 & 58.4 & 699.4 & 27.0 & 741.3 & 63.5 \\
\hline C18:1 Vaccenic & 45.6 & 1.9 & 46.2 & 3.9 & 45.1 & 1.7 & 51.1 & 6.4 \\
\hline C18:2 & 684.2 & 21.2 & 730.2 & 54.0 & 688.1 & 21.1 & 722.7 & 58.7 \\
\hline $\mathrm{C} 20: 0$ & 5.3 & 0.3 & 5.6 & 0.8 & 5.3 & 0.3 & 5.5 & 0.7 \\
\hline C18:3 DGLA & 12.9 & 0.7 & 13.9 & 1.7 & 12.7 & 0.7 & 16.8 & 2.0 \\
\hline C20:1 & 3.5 & 0.3 & 3.8 & 0.7 & 3.4 & 0.3 & 4.9 & 0.7 \\
\hline C18:3 ALA & 18.3 & 1.3 & 22.4 & 2.8 & 18.9 & 1.3 & 19.2 & 2.5 \\
\hline C20:2 & 3.6 & 0.3 & 4.1 & 0.8 & 3.5 & 0.3 & 4.8 & 0.9 \\
\hline $\mathrm{C} 22: 0$ & 15.4 & 0.7 & 15.0 & 2.0 & 15.4 & 0.7 & 14.8 & 2.2 \\
\hline C20:3 & 36.2 & 1.4 & 34.7 & 3.1 & 35.5 & 1.4 & 40.0 & 3.0 \\
\hline C20:4 & 204.9 & 6.6 & 230.7 & 14.2 & 205.5 & 6.1 & 240.6 & 24.1 \\
\hline $\mathrm{C} 22: 2$ & 0.1 & 0.1 & 0.0 & 0.0 & 0.1 & 0.1 & 0.0 & 0.0 \\
\hline $\mathrm{C} 24: 0$ & 11.4 & 0.5 & 11.7 & 1.1 & 11.4 & 0.5 & 11.9 & 1.3 \\
\hline C20:5 & 20.0 & 1.2 & 24.0 & 2.5 & 20.4 & 1.2 & 22.8 & 2.9 \\
\hline $\mathrm{C} 24: 1$ & 23.7 & 0.8 & 24.9 & 2.7 & 23.9 & 0.8 & 24.3 & 3.5 \\
\hline $\mathrm{C} 22: 4$ & 3.7 & 0.4 & 4.3 & 0.6 & 3.6 & 0.3 & 5.6 & 1.0 \\
\hline $\mathrm{C} 22: 5$ & 13.2 & 0.6 & 14.2 & 1.2 & 13.1 & 0.6 & 15.7 & 2.0 \\
\hline $\mathrm{C} 22: 6$ & 39.7 & 1.6 & 50.1 & 8.8 & 41.0 & 2.1 & 45.4 & 4.5 \\
\hline
\end{tabular}

Abbreviations: acute coronary syndrome (ACS), alpha-linolenic acid (ALA), cerebrovascular accident (CVA), dihommo gamma linolenic acid (DGLA), transient ischemic attack (TIA), standard error of the mean (SEM) 
Table 2: Plasma Oxylipin Concentration (nM) by Presence of Event

\begin{tabular}{|c|c|c|c|c|c|c|c|c|}
\hline Oxylipin & $\begin{array}{c}\text { No } \\
\text { Angina } \\
(\mathrm{n}=82)\end{array}$ & SEM & $\begin{array}{c}\text { Yes } \\
\text { Angina } \\
(\mathrm{n}=16)\end{array}$ & SEM & $\begin{array}{c}\text { No ACS } \\
(n=74)\end{array}$ & SEM & $\begin{array}{c}\text { Yes ACS } \\
(n=24)\end{array}$ & SEM \\
\hline 10-HDOHE & 0.4 & 0.1 & 0.9 & 0.5 & 0.4 & 0.1 & 0.9 & 0.4 \\
\hline 11,12-DiHETrE & 0.6 & 0.0 & 0.8 & 0.1 & 0.6 & 0.0 & 0.8 & 0.1 \\
\hline 11-HDOHE & 0.8 & 0.1 & 1.2 & 0.4 & 0.8 & 0.1 & 1.3 & 0.4 \\
\hline 11-HETE & 0.8 & 0.1 & 1.2 & 0.5 & 0.7 & 0.0 & 1.3 & 0.4 \\
\hline 12-HETE & 3.8 & 0.6 & 4.1 & 0.9 & 4.0 & 0.6 & 3.4 & 0.7 \\
\hline 12,13-DiHOME & 3.4 & 0.4 & 2.5 & 0.3 & 3.3 & 0.4 & 3.0 & 0.3 \\
\hline 12-HEPE & 0.8 & 0.1 & 1.3 & 0.4 & 0.8 & 0.2 & 1.1 & 0.3 \\
\hline 13-HODE & 10.1 & 1.0 & 9.2 & 1.0 & 10.2 & 1.0 & 9.3 & 0.9 \\
\hline 13-HDOHE & 0.3 & 0.1 & 0.5 & 0.3 & 0.2 & 0.0 & 0.6 & 0.3 \\
\hline 13-OXOODE & 9.0 & 2.2 & 6.7 & 0.8 & 9.3 & 2.5 & 6.4 & 0.7 \\
\hline 14,15-DiHETrE & 0.8 & 0.0 & 0.8 & 0.1 & 0.8 & 0.0 & 0.9 & 0.1 \\
\hline 14-HDOHE & 1.4 & 0.2 & 1.9 & 0.5 & 1.5 & 0.2 & 1.5 & 0.3 \\
\hline 15-HETrE & 0.5 & 0.1 & 0.9 & 0.4 & 0.5 & 0.1 & 1.0 & 0.3 \\
\hline 15-HETE & 1.1 & 0.1 & 1.5 & 0.4 & 1.1 & 0.1 & 1.5 & 0.4 \\
\hline 16-HDOHE & 0.3 & 0.1 & 0.6 & 0.4 & 0.2 & 0.0 & 0.7 & 0.3 \\
\hline 16-HETE & 0.1 & 0.0 & 0.3 & 0.1 & 0.1 & 0.0 & 0.2 & 0.1 \\
\hline 17-HDOHE & 0.9 & 0.1 & 1.3 & 0.8 & 0.7 & 0.1 & 1.5 & 0.6 \\
\hline 18-HEPE & 0.1 & 0.0 & 0.3 & 0.2 & 0.1 & 0.0 & 0.3 & 0.2 \\
\hline 18-HETE & 0.3 & 0.0 & 0.5 & 0.3 & 0.3 & 0.0 & 0.5 & 0.2 \\
\hline 19,20-DiHDPA & 1.5 & 0.1 & 1.6 & 0.2 & 1.5 & 0.1 & 1.5 & 0.1 \\
\hline 20-HDOHE & 0.4 & 0.1 & 0.7 & 0.4 & 0.3 & 0.0 & 0.6 & 0.3 \\
\hline 4-HDOHE & 0.6 & 0.1 & 0.8 & 0.3 & 0.5 & 0.1 & 1.0 & 0.4 \\
\hline 5-HETE & 1.3 & 0.1 & 1.9 & 0.7 & 1.2 & 0.1 & 2.1 & 0.6 \\
\hline 5,6-DiHETrE & 0.3 & 0.0 & 0.3 & 0.1 & 0.3 & 0.0 & 0.3 & 0.1 \\
\hline 5-HEPE & 0.6 & 0.1 & 1.1 & 0.5 & 0.5 & 0.1 & 1.1 & 0.4 \\
\hline 6keto-PGF ${ }_{1 \alpha}$ & 0.7 & 0.0 & 0.7 & 0.0 & 0.7 & 0.0 & 0.7 & 0.0 \\
\hline 7-HDOHE & 0.2 & 0.1 & 0.5 & 0.4 & 0.1 & 0.0 & 0.6 & 0.3 \\
\hline 8,9-DiHETrE & 0.2 & 0.0 & 0.3 & 0.1 & 0.2 & 0.0 & 0.3 & 0.1 \\
\hline 8-HETE & 0.7 & 0.1 & 1.0 & 0.4 & 0.6 & 0.1 & 1.1 & 0.3 \\
\hline 9-HODE & 8.8 & 0.9 & 8.4 & 1.2 & 8.9 & 1.0 & 8.2 & 0.9 \\
\hline 9,10,13-TriHOME & 5.5 & 2.1 & 2.1 & 0.3 & 5.9 & 2.3 & 2.0 & 0.2 \\
\hline 9,10-DIHOME & 3.7 & 0.4 & 3.0 & 0.5 & 3.7 & 0.5 & 3.1 & 0.4 \\
\hline 9,12,13-TriHOME & 3.2 & 1.1 & 1.6 & 0.3 & 3.4 & 1.2 & 1.6 & 0.2 \\
\hline 9-HOTrE & 0.8 & 0.1 & 0.9 & 0.2 & 0.7 & 0.1 & 1.0 & 0.2 \\
\hline Maresin & 27.6 & 4.4 & 20.6 & 6.1 & 26.5 & 4.6 & 26.3 & 6.6 \\
\hline $\mathrm{PGD}_{2}$ & 10.4 & 3.7 & 4.6 & 1.1 & 27.5 & 17.9 & 8.6 & 3.1 \\
\hline $\mathrm{PGE}_{2}$ & 0.3 & 0.0 & 0.4 & 0.0 & 0.3 & 0.0 & 0.4 & 0.0 \\
\hline $\mathrm{PGF}_{2 \alpha}$ & 0.3 & 0.1 & 0.1 & 0.1 & 0.3 & 0.0 & 0.3 & 0.1 \\
\hline $\mathrm{TXB}_{2}$ & 0.1 & 0.0 & 0.2 & 0.1 & 0.1 & 0.0 & 0.2 & 0.1 \\
\hline
\end{tabular}




\begin{tabular}{|c|c|c|c|c|c|c|c|c|}
\hline Oxylipin & $\begin{array}{l}\text { No TIA } \\
(\mathrm{n}=82)\end{array}$ & SEM & $\begin{array}{c}\text { Yes TIA } \\
(n=16)\end{array}$ & SEM & $\begin{array}{c}\text { No CVA } \\
(\mathrm{n}=88)\end{array}$ & SEM & $\begin{array}{c}\text { Yes CVA } \\
(n=10)\end{array}$ & SEM \\
\hline 10-HDOHE & 0.5 & 0.1 & 0.4 & 0.1 & 0.5 & 0.1 & 0.9 & 0.4 \\
\hline 11,12-DiHETrE & 0.6 & 0.0 & 0.8 & 0.1 & 0.7 & 0.0 & 0.7 & 0.1 \\
\hline 11-HDOHE & 0.9 & 0.1 & 0.8 & 0.3 & 0.8 & 0.1 & 1.5 & 0.6 \\
\hline 11-HETE & 0.8 & 0.1 & 0.8 & 0.1 & 0.8 & 0.1 & 1.3 & 0.6 \\
\hline 12-HETE & 3.9 & 0.6 & 3.5 & 0.8 & 3.9 & 0.5 & 4.0 & 1.1 \\
\hline 12,13-DiHOME & 3.3 & 0.4 & 2.7 & 0.2 & 3.2 & 0.3 & 3.1 & 0.5 \\
\hline 12-HEPE & 0.9 & 0.2 & 0.8 & 0.3 & 0.9 & 0.1 & 1.3 & 0.5 \\
\hline 13-HODE & 9.8 & 0.9 & 10.8 & 1.3 & 10.1 & 0.9 & 9.4 & 1.4 \\
\hline 13-HDOHE & 0.3 & 0.1 & 0.2 & 0.1 & 0.3 & 0.1 & 0.5 & 0.3 \\
\hline 13-OXOODE & 9.0 & 2.2 & 6.9 & 1.1 & 8.9 & 2.1 & 5.9 & 1.0 \\
\hline 14,15-DiHETrE & 0.8 & 0.0 & 0.8 & 0.1 & 0.8 & 0.0 & 0.9 & 0.1 \\
\hline 14-HDOHE & 1.5 & 0.2 & 1.5 & 0.5 & 1.5 & 0.2 & 1.8 & 0.5 \\
\hline 15-HETrE & 0.6 & 0.1 & 0.5 & 0.1 & 0.6 & 0.1 & 0.9 & 0.4 \\
\hline 15-HETE & 1.2 & 0.1 & 1.2 & 0.1 & 1.1 & 0.1 & 1.8 & 0.5 \\
\hline 16-HDOHE & 0.4 & 0.1 & 0.3 & 0.1 & 0.3 & 0.1 & 0.6 & 0.3 \\
\hline 16-HETE & 0.1 & 0.0 & 0.2 & 0.0 & 0.1 & 0.0 & 0.4 & 0.1 \\
\hline 17-HDOHE & 0.9 & 0.2 & 1.0 & 0.4 & 0.9 & 0.2 & 1.4 & 0.8 \\
\hline 18-HEPE & 0.1 & 0.0 & 0.1 & 0.1 & 0.1 & 0.0 & 0.4 & 0.2 \\
\hline 18-HETE & 0.3 & 0.1 & 0.3 & 0.1 & 0.3 & 0.1 & 0.5 & 0.2 \\
\hline 19,20-DiHDPA & 1.5 & 0.1 & 1.7 & 0.2 & 1.5 & 0.1 & 1.8 & 0.2 \\
\hline 20-HDOHE & 0.4 & 0.1 & 0.5 & 0.2 & 0.4 & 0.1 & 0.6 & 0.2 \\
\hline 4-HDOHE & 0.6 & 0.1 & 0.5 & 0.1 & 0.5 & 0.1 & 1.3 & 0.7 \\
\hline 5-HETE & 1.4 & 0.2 & 1.4 & 0.3 & 1.3 & 0.1 & 2.3 & 0.9 \\
\hline 5,6-DiHETrE & 0.3 & 0.0 & 0.2 & 0.0 & 0.3 & 0.0 & 0.3 & 0.1 \\
\hline 5-HEPE & 0.7 & 0.1 & 0.7 & 0.2 & 0.6 & 0.1 & 1.4 & 0.6 \\
\hline 6keto-PGF $1 \alpha$ & 0.7 & 0.0 & 0.6 & 0.1 & 0.7 & 0.0 & 0.7 & 0.1 \\
\hline 7-HDOHE & 0.3 & 0.1 & 0.2 & 0.1 & 0.2 & 0.1 & 0.6 & 0.4 \\
\hline 8,9-DiHETrE & 0.2 & 0.0 & 0.2 & 0.0 & 0.2 & 0.0 & 0.3 & 0.1 \\
\hline 8-HETE & 0.8 & 0.1 & 0.7 & 0.2 & 0.7 & 0.1 & 1.3 & 0.5 \\
\hline 9-HODE & 8.6 & 0.9 & 9.2 & 1.2 & 8.8 & 0.8 & 8.1 & 1.4 \\
\hline 9,10,13-TriHOME & 5.4 & 2.1 & 2.6 & 0.4 & 5.3 & 1.9 & 2.2 & 0.4 \\
\hline 9,10-DIHOME & 3.6 & 0.4 & 3.5 & 0.6 & 3.6 & 0.4 & 3.5 & 0.7 \\
\hline 9,12,13-TriHOME & 3.1 & 1.1 & 2.0 & 0.3 & 3.1 & 1.0 & 1.7 & 0.3 \\
\hline 9-HOTrE & 0.8 & 0.1 & 0.9 & 0.2 & 0.8 & 0.1 & 0.8 & 0.3 \\
\hline Maresin & 26.2 & 4.4 & 27.8 & 6.9 & 26.2 & 4.0 & 28.5 & 12.0 \\
\hline $\mathrm{PGD}_{2}$ & 26.2 & 16.1 & 5.7 & 1.0 & 23.9 & 15.0 & 13.9 & 7.3 \\
\hline $\mathrm{PGE}_{2}$ & 0.3 & 0.0 & 0.4 & 0.1 & 0.3 & 0.0 & 0.4 & 0.0 \\
\hline $\mathrm{PGF}_{2 \alpha}$ & 0.3 & 0.1 & 0.3 & 0.1 & 0.2 & 0.0 & 0.6 & 0.3 \\
\hline $\mathrm{TXB}_{2}$ & 0.1 & 0.0 & 0.3 & 0.1 & 0.1 & 0.0 & 0.2 & 0.1 \\
\hline
\end{tabular}

Note: Plasma oxylipin concentrations in the FlaxPAD trial divided based on placebo or flaxseed group at baseline and 6 months have been previously published (Caligiuri et al. Hypertension. 2014; 64: 53-59). Abbreviations: 6 keto (6k), acute coronary syndrome (ACS), cerebrovascular accident (CVA), dihommo gamma linolenic acid 
(DGLA), dihydroxydocosapentanoic acid (DiHDPA), dihydroxyeicosatrienoic acid (DiHETrE), dihydroxyoctadecenoic acid (DiHOME), HETrE (hydroxyeicosatrienoic acid), hydroxydocosahexaenoic acid, (HDOHE), hydroxyeicosapentaenoic acid (HEPE), hydroxyeicosatetraenoic acid (HETE), hydroxyeicosatrienoic acid (HETrE), hydroxyoctadecadienoic acid (HODE), hydroxyoctadecatrienoic acid (HOTrE), oxooctadecadienoic acid (OXOODE), prostaglandin (PG), standard error of the mean (SEM), transient ischemic attack (TIA), trihydroxyoctadecenoic acid (TriHOME), thromboxane (TX). 